\title{
Evaluation of the 183-D Water Filtration Facility for Bat Roosts and Development of a Mitigation Strategy, 100-D Area, Hanford Site
}

March 2011

For Public Release

\section{Washington Closure Hanford}

Prepared for the U.S. Department of Energy, Richland Operations Office Office of Assistant Manager for River Corridor 
TRADEMARK DISCLAIMER

Reference herein to any specific commercial product, process, or service by trade name, trademark, manufacturer, or otherwise, does not necessarily constitute or imply its endorsement, recommendation, or favoring by the United States Government or any agency thereof or its contractors or subcontractors.

This report has been reproduced from the best available copy.

Printed in the United States of America 


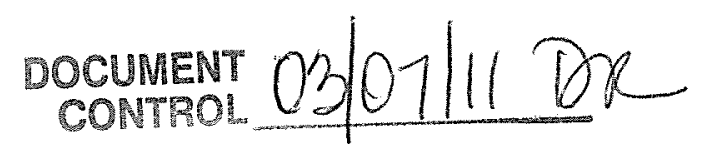

WCH -438

Rev. 0

\section{STANDARD APPROVAL PAGE}

Title: $\quad$ Evaluation of the 183-D Water Filtration Facility for Bat Roosts and Development of a Mitigation Strategy, 100-D Area, Hanford Site

Author Name: C. T. Lindsey, K. A. Gano, and J. G. Lucas

Approval: $\quad$ Jill Thomson, Manager, Environmental Services

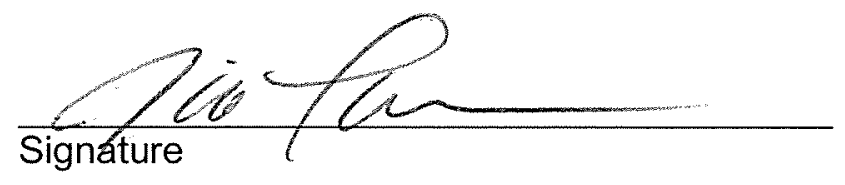

$\frac{3 / 7 / 11}{\text { Date }}$ 
WCH-438

Rev. 0

\section{River Corridor Closure Contract}

\section{Evaluation of the 183-D Water Filtration Facility for Bat Roosts and Development of a Mitigation Strategy, 100-D Area, Hanford Site}

March 2011
Authors:
C. T. Lindsey
K. A. Gano
J. G. Lucas

For Public Release 


\section{TABLE OF CONTENTS}

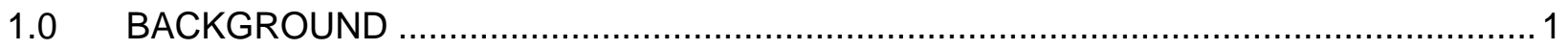

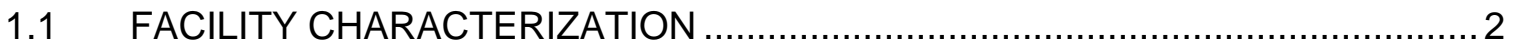

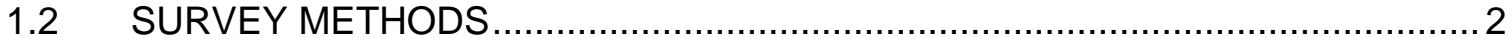

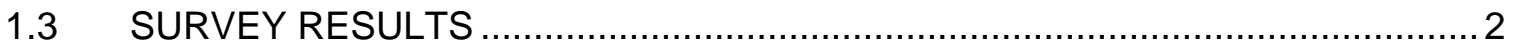

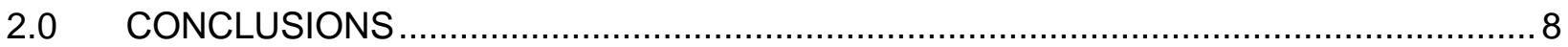

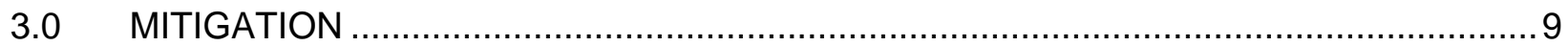

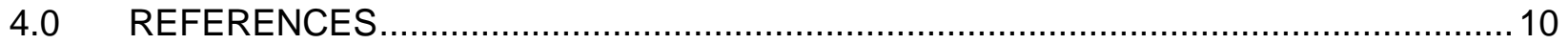

\section{FIGURES}

1. AnaBat Acoustic Monitoring Around 183-D. ................................................................ 3

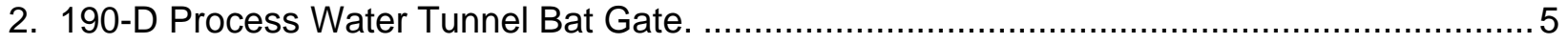

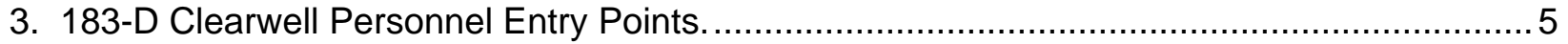

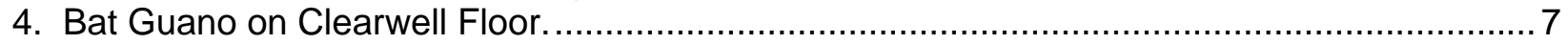

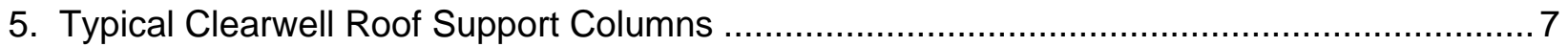

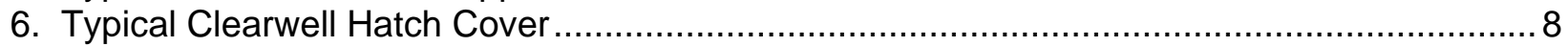




\subsection{BACKGROUND}

The 183-D Water Filtration Facility is located in the 100-D Area of the Hanford Site, north of Richland, Washington. It was used to provide filtered water for cooling the 105-D Reactor and supplying fire-protection and drinking water for all facilities in the 100-D Area. The facility has been inactive since the 1980s and is now scheduled for demolition. Therefore, an evaluation was conducted to determine if any part of the facility was being used as roosting habitat by bats. The 183-D Facility was part of a larger evaluation for bat roosts (Evaluation of Retired Facilities for Bat Roosts [WCH-450, in preparation]) that was conducted on the buildings remaining in the Washington Closure Hanford deactivation, decontamination, decommissioning, and demolition (D4) schedule. The work was started during the spring of 2009. The 183-D Facility was selected for further investigation due to the large size and complexity of the facility, the presence of openings that could allow bats to enter numerous parts of the facility, and because of a history of bat roosts found in similar retired facilities in the 100 Areas.

Before impacting any biological resource during a remediation or demolition project, it is necessary to understand the implications of the planned actions. Species present must be identified to determine if any are listed on state or federal protection lists. If sensitive species are present, alternatives must be developed to mitigate the impacts. This process is required as part of the implementation of the National Environmental Policy Act (NEPA) while conducting remediation projects under the Comprehensive Environmental Response, Compensation, and Liability Act of 1980 (CERCLA). DOE/RL-96-32, Hanford Site Biological Resources Management Plan, provides guidance for determining which biological resources require mitigation on the Hanford Site. The document also provides guidance on the various levels of mitigation in order to protect species of concern and protect loss of critical habitat.

The Washington State Department of Fish and Wildlife (WDFW) has two listings for protecting plant and animal species: the Species of Concern (SOC) list and the Priority Habitats and Species (PHS) program. Species of Concern are also considered Priority Species under the PHS program. Many of the bat species known to occur on the Hanford Site are included on the Washington State Priority Species list.

The SOC list (available at: http://wdfw.wa.gov/) includes all state endangered, threatened, sensitive, and candidate species, as well as facilitates management and development of species recovery plans.

The following text is a description of the PHS program:

"The PHS List is a catalog of habitats and species considered to be priorities for conservation and management. Priority species require protective measures for their perpetuation due to their population status, sensitivity to habitat alteration, and/or recreational, commercial, or tribal importance. Priority species include State Endangered, Threatened, Sensitive, and Candidate species; animal aggregations considered vulnerable; and those species of recreational, commercial, or tribal importance that are vulnerable." 


\section{$1.1 \quad$ FACILITY CHARACTERIZATION}

The 100-D Water Treatment Facility consists of the 181-D River Pumphouse that pumped water from the Columbia River to the 182-D Settling Basins. The open air settling basins are $229 \mathrm{~m}$ long by $28 \mathrm{~m}$ wide by $5.0 \mathrm{~m}$ deep and were designed to hold 95,600,000 L of water. The purpose of the settling basins was to allow heavier particulate matter to settle out before the water entered the 183-D Water Filtration Facility. The filtration facility is located directly west of the 105-D Reactor Building and was designed to filter river water to be used for cooling the reactor. It consists of the following structures: the headhouse, flocculation and sedimentation basins, filter building, clearwells, and pump house. The footprint of the 183-D Facility is approximately $24,300 \mathrm{~m}^{2}$. The headhouse is a three-story steel-framed, reinforced concrete and cinder-block building used for the storage, preparation, and addition of alum, sulfuric acid, ferrous sulfate, and chlorine for water treatment. There are 12 flocculation and sedimentation basins that are each approximately $35 \mathrm{~m}$ long, $14 \mathrm{~m}$ wide, $3 \mathrm{~m}$ deep, and constructed of reinforced concrete. The basins received water from a distribution flume that fed twelve 208,000-L flocculation chambers. Each chamber contained a steel mixing paddle wheel. The water moved from the flocculation chamber into the 1,900,000-L sedimentation basin. At the end of these basins is an overflow weir where the water entered the filter plant. The filter building contained 12 filter systems, each with layers of graded gravel, sand, and crushed and graded anthracite coal. The output capacity of the filter plant was originally $36,000 \mathrm{gal} / \mathrm{min}$. From the filter plant, the water entered the two reinforced concrete clearwells that each stored $17,000,000 \mathrm{~L}$ of treated water that was pumped as needed to the reactor cooling system via steel water storage tanks in the 190-D Building.

\subsection{SURVEY METHODS}

A graded approach was used to conduct the bat surveys during this investigation. First, a walkdown of the exterior was conducted to inspect for likely roosting habitat, bat access to the buildings, and any presence of fecal pellets that would indicate bat use. Remote monitoring was then conducted using an AnaBat ${ }^{\mathrm{TM}}$ SD2 Bat Detector. When the presence of bats was established with the AnaBat detector, further investigations were conducted using internal and external walkdowns, manual and automated acoustic monitoring with a Pettersson D240x ultrasound detector, ultrasound recording analysis, mist netting that included morphological measurements of captured bats, and infrared video recording.

\subsection{SURVEY RESULTS}

An AnaBat acoustic detector was placed at several locations during the investigation around the 183-D Facility to document relative levels of activity around the structure. Figure 1 shows the average number of calls per night, also known as bat passes, recorded around the facility in 2009 and 2010. 
Figure 1. AnaBat Acoustic Monitoring Around 183-D.

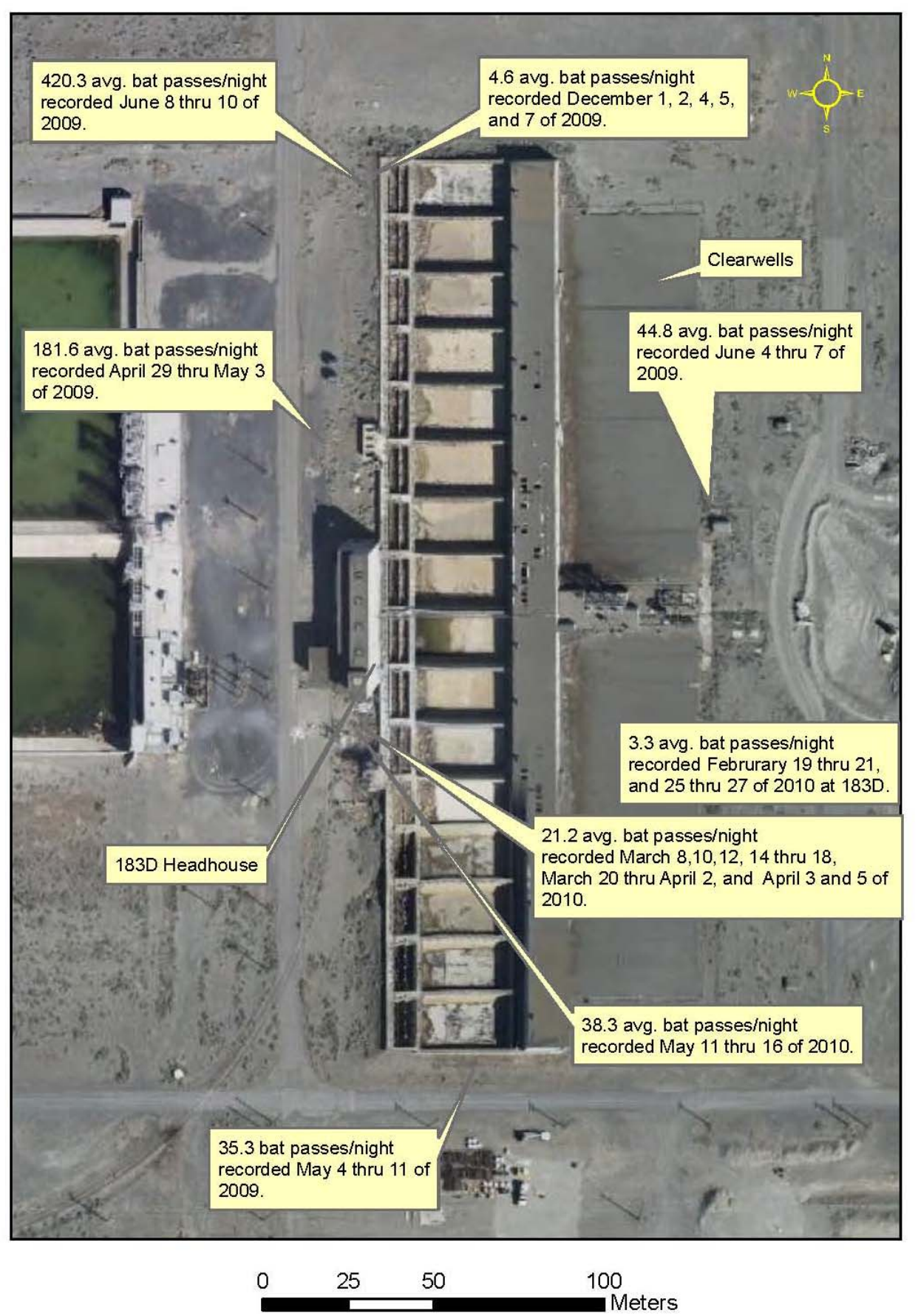

The number of calls recorded at this facility was extremely high compared to monitoring at other locations around the Hanford Site. For example, monitoring at the 183-H Clearwell showed an average of nine bat passes/night recorded April 23, 24, 26, 27, and 29, 2009, whereas 183-D Facility had an average 181.3 bat passes/night recorded during a similar time period. The high level of activity recorded around the headhouse portion of the facility and the presence of an open door on the third level of the headhouse prompted further evaluation concentrating 
on this portion of the facility. Mist netting, infrared video recording, and acoustic monitoring with a Pettersson D240x was performed on May 20, 2009. During the mist netting event, 29 Yuma myotis (Myotis yumanensis) were captured between 21:12 and 21:15 hours. This is an extremely high rate of capture compared to other mist netting events performed around the Hanford Site. Analysis of the acoustic data showed that in addition to the Yuma myotis, pallid bats (Antrozous pallidus) and, to a lesser extent canyon bats (Parastrellus hesperus), were also present in the area. A juvenile pallid bat was also found on one of the mobile offices at the 100-D Area on July 15, 2009, indicating a maternity roost was likely in the area. This information led us to further investigate the potential for a pallid bat roost and/or a Yuma myotis roost at the 183-D Facility.

A walkdown of the interior of the 183-D Headhouse was performed on May 17, 2010. Small accumulations of bat guano were found throughout the building. The amount of guano found inside the structure did not indicate that a maternity colony was using the portions of the building that were accessible to the survey team.

During subsequent video recording on June 9,2010, bats were observed emerging from a small crack in the cinderblock wall the 183-D Headhouse. The size and appearance of the bats, and the audible presence of pallid bat social calls, showed that this crack was the entrance to a pallid bat roost. Analysis of the video recording performed on June 9, 2010, showed 14 pallid bats exiting the crack. During a follow-up survey on June 23, emergence observations performed at the same location showed that pallid bats began leaving the roost 1 hour after sunset.

Pallid bats are a state monitor species, and are on the priority species list for the WDFW. Their colonial roost sites are considered priority habitats. For these reasons, it was necessary to develop a mitigation plan for potential impacts to the colony at the 183-D Facility.

In addition to the pallid bats observed exiting the 183-D Building shortly after sunset, bats were observed entering the open door on the third floor of the 183-D Building. No observations were made that would indicate an emergence from a colony inside the building, but the bats entering the building indicate that they may be using the facility as a night roost. Night roosts are used by bats between feeding bouts, and may be important for digestion, energy conservation, shelter from predators, and for information exchange and social interaction. Bats have shown habitual use of night roosts from day to day and year to year (Ormsbee et al. 2007). Night roosts are considered a priority habitat under WDFW's PHS program. Due to the large number of Yuma myotis captured during mist netting near the 183-D Facility, and the presence of echolocation calls with a characteristic frequency near $50 \mathrm{kHz}$, it was determined that the bats using the facility are Yuma myotis.

It is possible that the bats entering the 183-D Headhouse were emerging from another part of the 183-D Facility, from the 190-D/DR Process Water Tunnels (a known roost site), or from an additional unknown roost. An emergence count of Yuma bats was conducted on July 7, 2010, at the 190-D Process Water Tunnel bat gate. Approximately 340 bats were counted leaving the roost. This bat gate is approximately $400 \mathrm{~m}$ southeast of the 183-D Headhouse (Figure 2). As the bats emerged from the bat gate, they most often flew in the direction of the water treatment plant and the sedimentation basins. Typically, when bats fist emerge from a roost, they fly to the nearest water source to get a drink and begin foraging for insects. This could explain some of the bats observed flying around and into the door on the third floor of the headhouse. 
Figure 2. 190-D Process Water Tunnel Bat Gate.

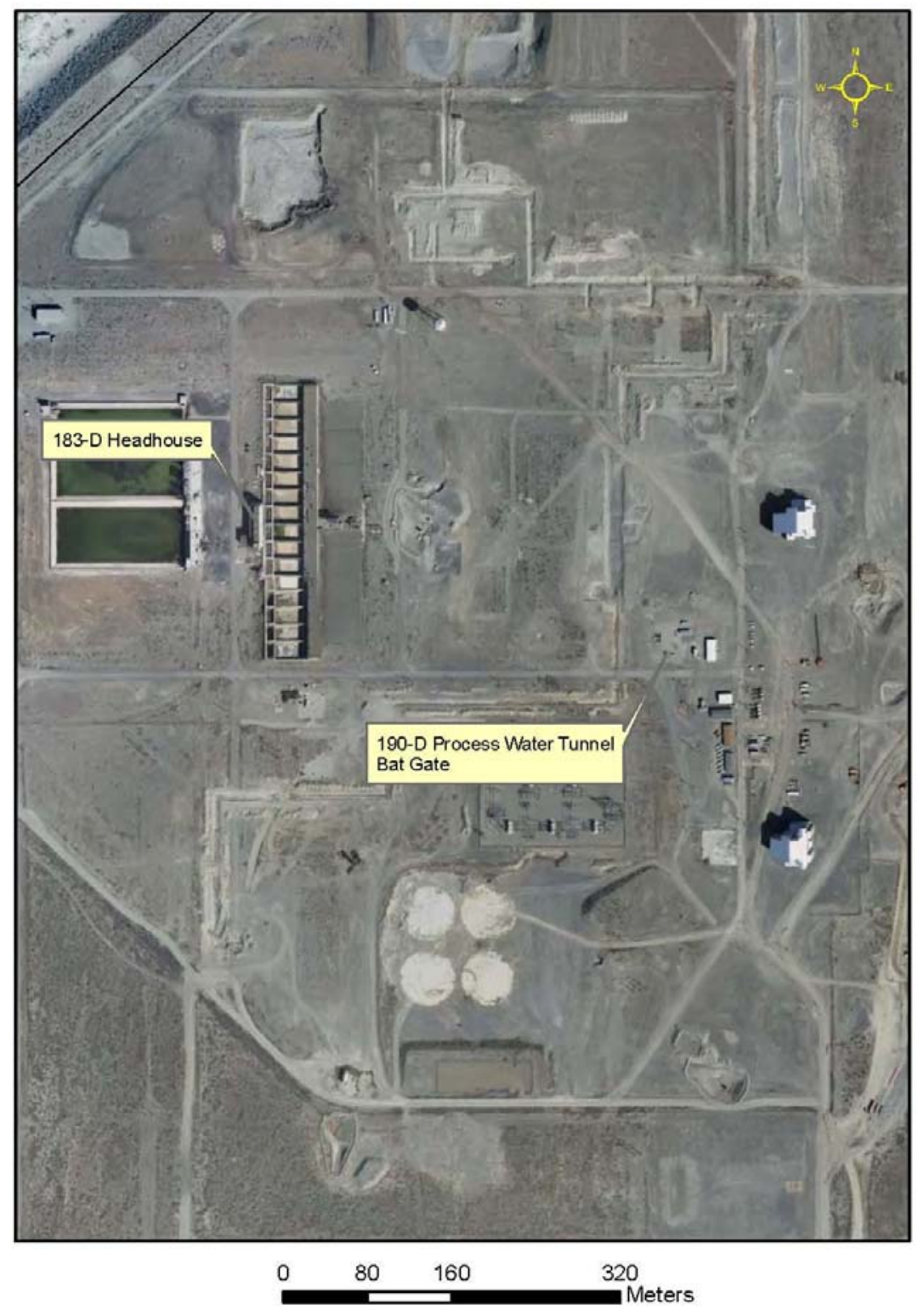

An entry into the 183-D Clearwells and connecting flumes was made on October 25, 2010, in order to assess these areas for the presence of bats. Entry was made at two locations using clearwell roof hatches (Figure 3). The interior and floor areas of both clearwells were inspected, along with associated connecting flumes. Bat guano was observed throughout the clearwells and connecting flumes, but no bats were observed during this inspection. No large localized accumulations of guano or urine staining were observed in potential bat roosting areas (under hatch covers and on roof support columns) in the clearwells that would suggest the presence of 
a maternity roost. The scattered guano throughout the facility does indicate that bats are using the buildings on a limited basis. The bats using the clearwells are potentially solitary individuals using the structure as a day or night roost. Figures 4 through 6 show photos of the inspection areas.

Figure 3. 183-D Clearwell Personnel Entry Points.

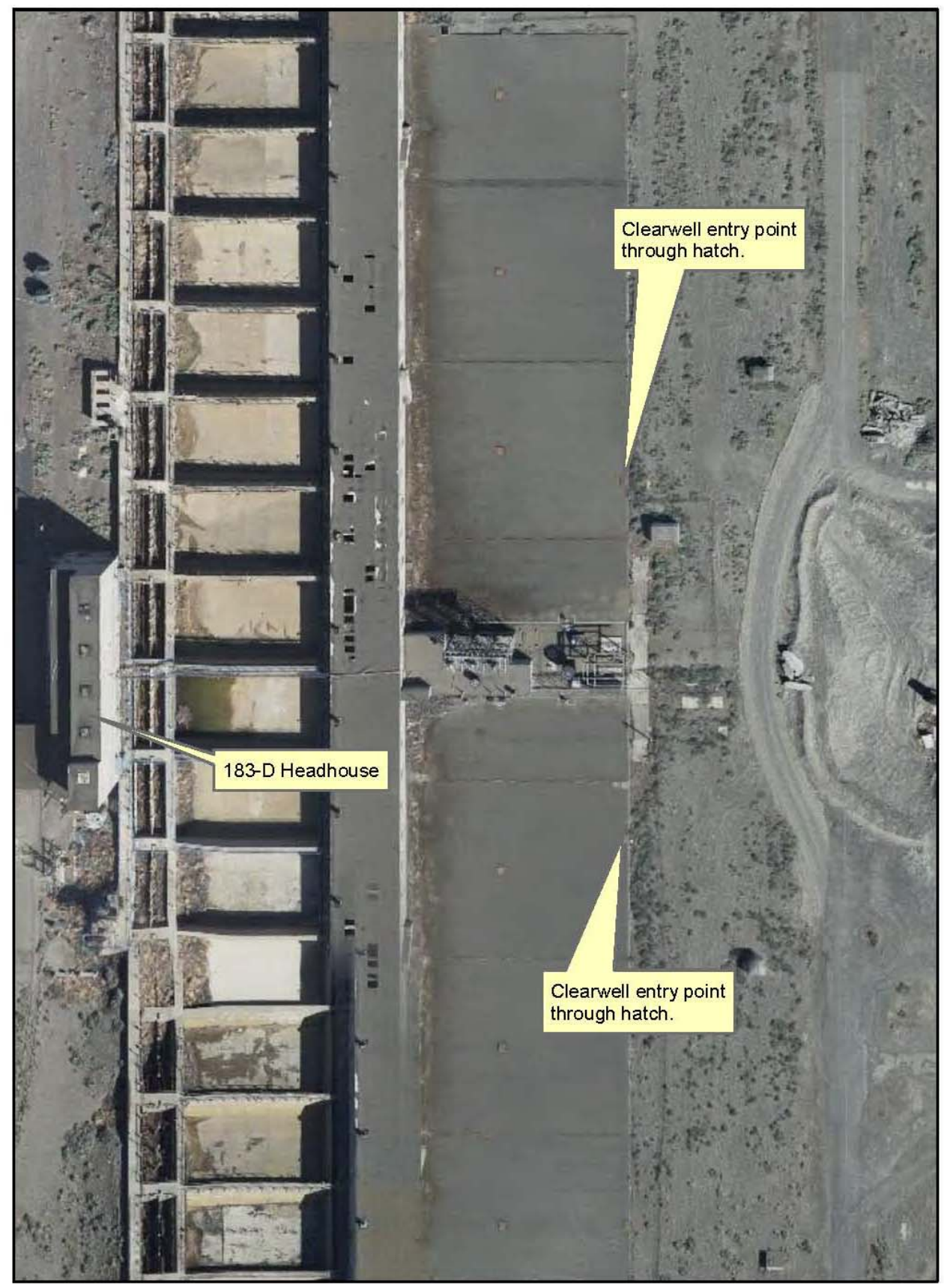


Figure 4. Bat Guano on Clearwell Floor.

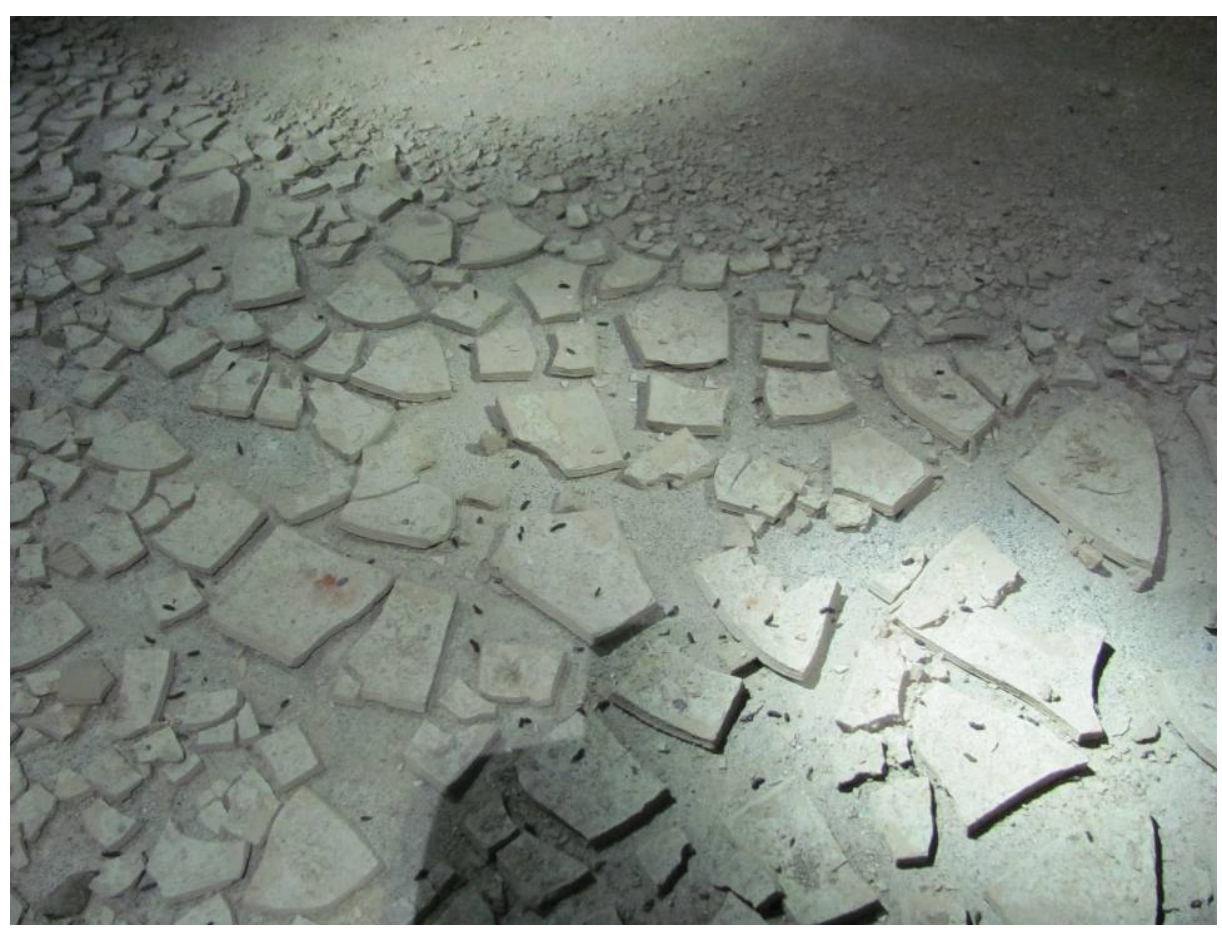

Figure 5. Typical Clearwell Roof Support Columns (no urine staining observed to indicate roosting).

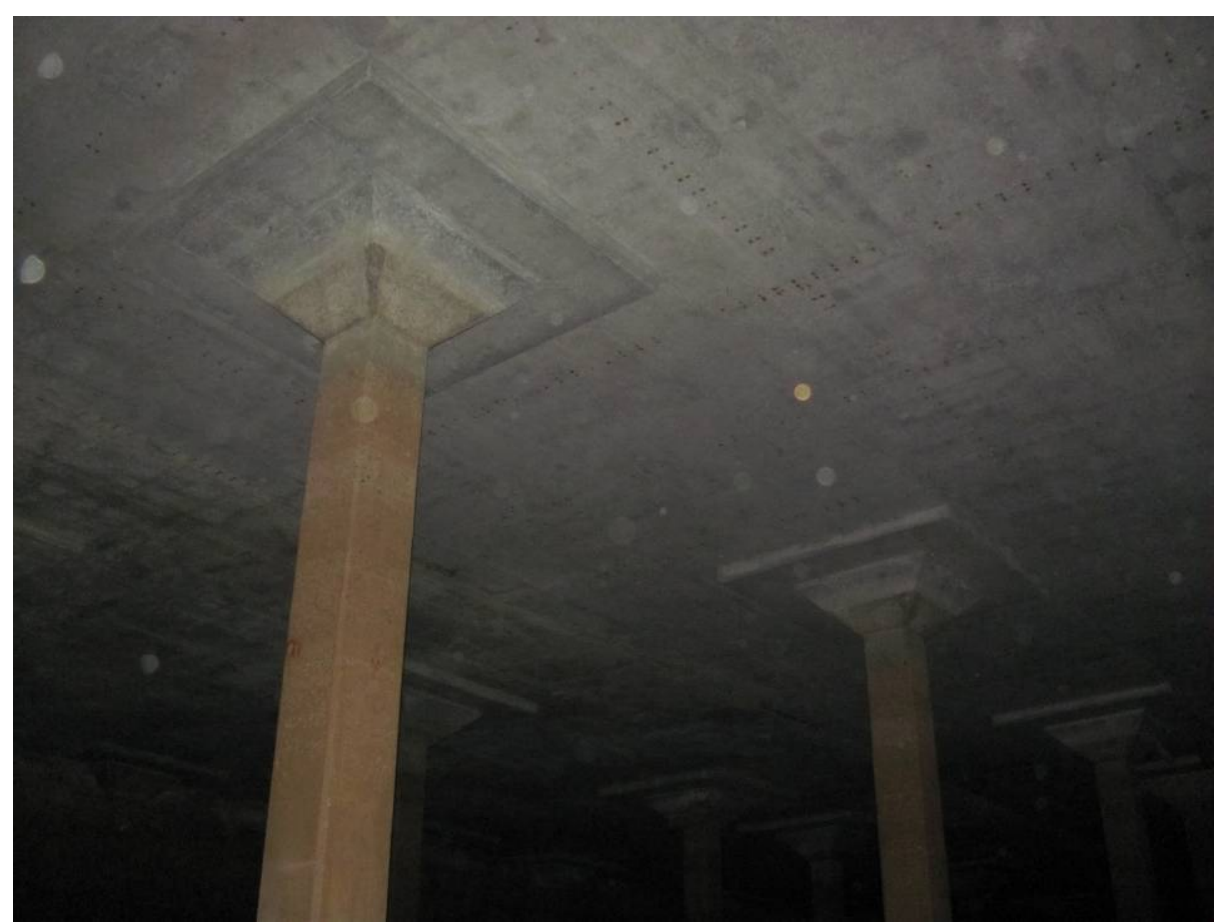

Evaluation of the 183-D Water Filtration Facility for Bat Roosts and Development of a Mitigation Strategy, 100-D Area, Hanford Site. 


\section{Figure 6. Typical Clearwell Hatch Cover (no urine staining observed).}

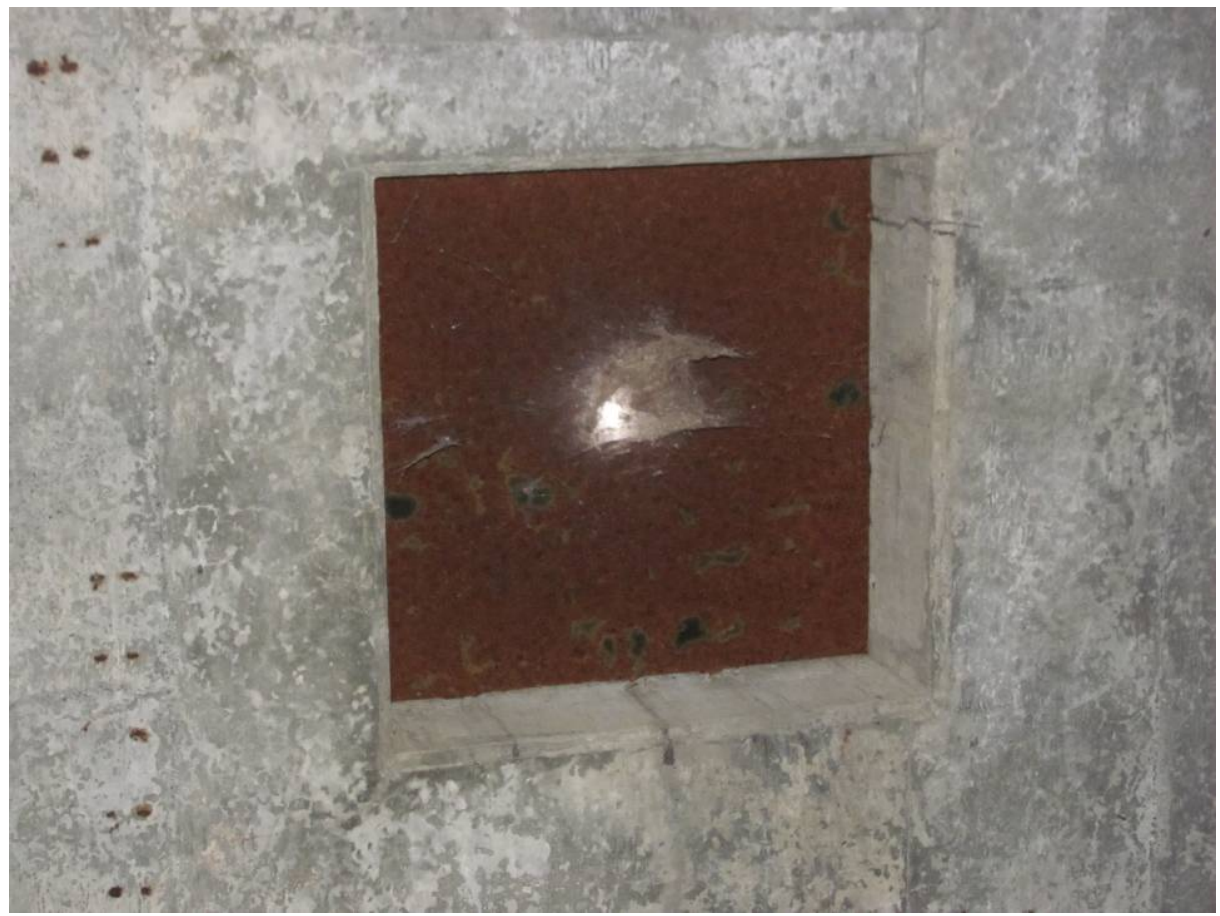

\subsection{CONCLUSIONS}

The acoustic monitoring data indicated that the majority of the bat activity was centered around the headhouse. Analysis of the acoustic data indicated that most of the bats observed were Yuma myotis, followed by pallid bats, and a small number of canyon bats. It is very likely that Yuma myotis are using the headhouse for a night roost and possibly an undiscovered maternity roost. A maternity roost of pallid bats was observed emerging from a crack in the cinder block on the south side of the headhouse. Because pallid bats are listed by the state of Washington as a Priority Species, mitigation is required according to DOE/RL-96-32 to maintain the viability of this colony. All portions of the 183-D Complex could not be surveyed (e.g., filter building, flumes) because of concerns for personnel safety and inaccessibility. Due to this limitation, and the complexity of the 183-D Facility, there is the potential that other roost sites exist in inaccessible portions of the facility. 


\subsection{MITIGATION}

Mitigation for biological resources includes avoidance of impacts, minimization of impacts, and rectification or replacement of habitat lost due to an impact. The level of mitigation employed depends on the species involved and the degree of disturbance that will be caused by the project. The demolition of the 183-D Water Treatment Facility will have a significant impact on the maternity roost of pallid bats and night roosts of other bats if mitigation measures are not taken. Mitigation actions must include avoidance of disturbance to the maternity roost while the bats are present (March to October) and long-term preservation of a roost site. Demolition activities should begin by November 1 when the bats leave for their winter roost elsewhere. Demolition activities of the headhouse should be completed and a replacement roost site constructed and in place by March 1. Because of the importance of this site to multiple species of bats, the replacement roost should be designed to accommodate multiple species.

Several demolition and mitigation alternatives have been considered as part of this evaluation and a preferred mitigation action selected. The following alternatives were evaluated considering direct impacts to the bat colonies, DOE's cleanup mission, and long-term roost viability:

1. Leave the entire 183-D Complex in place.

2. Demolish the entire 183-D Facility.

3. Leave the headhouse and demolish the remainder of the facility.

4. Leave one clearwell and demolish the remainder of the facility.

5. Demolish the entire 183-D Facility and construct an alternative roost near the headhouse.

6. Demolish the 183-D Facility, construct an alternative roost near the headhouse and leave one clearwell.

Alternative 6 was selected as the preferred alternative because it is the only choice that provides no net loss to the roosting habitat. Constructing an alternative roost site in the vicinity of the headhouse would replace the current pallid bat maternity roost and create a structure without future hazards to people. Pallid bats prefer above ground structures such as rock outcrops and abandoned buildings. Therefore, providing an aboveground roost structure would replace habitat for the pallid bats and many other species that utilize structures. Plans are available for a design that consists of a small cinder-block building approximately $2 \mathrm{~m}$ by $2 \mathrm{~m}$ and $4.5 \mathrm{~m}$ tall.

The alternative roost is expected to provide suitable habitat for the pallid bat maternity colony, but it is unknown whether this would be a suitable replacement for the Yuma myotis. Although Yuma myotis are known to have maternity colonies in the 190-D tunnels, it is apparent that these bats, or bats from another Yuma myotis colony, value the 183-D Headhouse as a night roost. Because night roosts are critically important to bats, it is necessary to mitigate for this impact. Yuma myotis are known to night roost in the 183-F Clearwell, therefore, leaving one of the 183-D clearwells intact and opening it up for bats to use would mitigate for the loss of the 183-D Headhouse night roost for the Yuma myotis. In addition, this structure would mitigate for 
any impacts to undiscovered roost sites in the headhouse, associated flumes, and the filter building. This would have the benefit of creating another very large roost site similar to the one at the 183-F Water Treatment Facility (Gano et al. 2009).

Ensuring no net loss of roosting habitat is becoming critically important to the survival of several species of bats in the United States. A lethal disease known as White-Nose Syndrome (WNS) is affecting several species of bats in the eastern U.S. and is spreading west. A very closely related species, the little brown bat (Myotis lucifigus), once considered one of the most abundant species in North America, was proposed for an emergency listing as an endangered species in January 2011. A recent study of the effects of WNS on little brown bats (Frick et al. 2010) concluded that "due to WNS, regional extinction will occur in the species' northeastern core range by 2026 , if not sooner - and rangewide extinction could very likely follow in a short time based on known and expected WNS infection rates."

With such devastating impact from WNS, it is becoming extremely important to preserve known myotis bat habitat. Yuma myotis have not yet been observed to contract WNS because they are predominantly a western species. However, because they are very closely related to the little brown bat they may be similarly affected if WNS spreads to the west coast. Since the disease was first discovered in New York in February 2006, it has spread west to Oklahoma in 2010.

\subsection{REFERENCES}

Comprehensive Environmental Response, Compensation, and Liability Act of 1980, 42 U.S.C. 9601 , et seq.

DOE/RL-96-32, 2001, Hanford Site Biological Resources Management Plan, Rev. 0 , U.S. Department of Energy, Richland Operations Office, Richland, Washington.

Frick, W. F., J. F. Pollock, A. Hicks, K. Langwig, D. S. Reynolds, G. G. Turner, C. Butchowski, and T. H. Kunz, 2010, An Emerging Disease Causes Regional Population Collapse of a Common North American Bat Species. Science, 329:679-682 (Aug. 2010).

Gano, K. A., J. G. Lucas, and C. T. Lindsey, 2009, Identification and Protection of a Bat Colony in the 183-F Clearwell: Mitigation of Bat Habitat on the Hanford Site, WCH-312, Washington Closure Hanford, Richland, Washington.

Ormsbee, P. C., J. D. Kiser, and S. I. Perlmeter, 2007, "Importance of Night Roosts to the Ecology of Bats," Bats in Forests, Conservation and Management, John Hopkins University Press, Baltimore, Maryland. 


\section{DISTRIBUTION}

U.S. Department of Energy

$\underline{\text { Richland Operations Office }}$

R. F. Guercia

A3-04

T. C. Post

J. P. Neath

D. C. Ward

Washington Closure Hanford

M. A. Allen

M. D. Flannery

K. A. Gano (3)

A. L. Johnson

W. F. Johnson

R. J. Landon

J. E. Laurenz

C. T. Lindsey (3)

J. G. Lucas (3)

D. W. Martin

C. D. McCurley

D. E. Reese

D. G. Saueressig

B. D. Smith

G. B. Snow

J. E. Thomson

D. J. Warren

W. J. West

D. M. Yasek

WDOE

F. W. Bond (4)

Document Control

DOE-RL Public Reading Room

Hanford Technical Library
A3-04

A3-04

A5-15

$\times 5-51$

$\times 5-50$

$\mathrm{H} 4-26$

$\mathrm{H} 4-26$

$\mathrm{H} 4-22$

$\mathrm{H} 4-21$

X9-08

$\mathrm{H} 4-26$

$\mathrm{H} 4-22$

X9-08

$\times 5-50$

$\times 5-50$

N3-30

L7-11

L7-11

H4-21

X5-50

H4-26

H4-22

$\mathrm{HO}-57$

H4-11

$\mathrm{H} 2-53$

P8-55 